\title{
Opening a New Gate to Glass preservative with Long- lasting Antimicrobial Activity as replacement of Parabens
}

\author{
Eva de Lucas-Gil ${ }^{+}, \|^{*}$, Fernando Rubio-Marcos ${ }^{\dagger *}$, Pilar Leret ${ }^{\S}$, Blanca Motos-Pérez $z^{\S}$, \\ Mercedes Monte-Serrano", Javier Menéndez"l and José F. Fernández ${ }^{\dagger}$
}

tElectroceramic Department, Instituto de Cerámica y Vidrio, CSIC, Kelsen 5, 28049 Madrid, Spain

"NanoBioMatters Bactiblock, NanoBioMatters Industries S.L. Louis Pasteur 11, 46980 Paterna, Valencia, Spain

\$Research \& Development Division, Advanced Dispersed Particles S.L. Oro 45, nave 14, Colmenar Viejo, 28770, Madrid, Spain

\begin{abstract}
In the last few years, the rapid and continuing emergence of antibiotic resistance for microbial pathogens has questioned the future utility of antibiotics. Thus, the discovery of new antimicrobials is highly desired to fight microorganisms with multi-drug resistant capability. Here, we have used an inorganic UV filter as a model system to investigate the behaviour of a new preservative, based on Ag-Zn cations, to replace parabens in sunscreens. The new glass preservative is incorporated to the UV filter composite by using an easy and eco-friendly method based on a dry nanodispersion. The Challenge Test clearly demonstrates a robust toxicity towards microorganisms both the resistant bacteria and the fungi. This stimulant behavior can be explained by coupling between the antimicrobial activity of the $\mathrm{Ag}^{+}$and the antifungal activity of $\mathrm{Zn}^{+2}$. Importantly, leaching assays show that the controlled released of these cations over time results in a long-lasting antimicrobial property, pointing out that this material is a promising paraben-free candidate.
\end{abstract}

KEYWORDS: Ag cation, Zn cation, Antimicrobial activity, Paraben-free, Sunscreens 
E. de Lucas-Gil, F. Rubio-Marcos, P. Leret, B. Motos-Pérez, M. Monte-Serrano, J. Menéndez, J.F. Fernández, Opening a New Gate to Glass Preservative with Long-Lasting Antimicrobial Activity as Replacement of Parabens, ACS Sustain. Chem. Eng. 5 (2017) $294-302$. doi:10.1021/acssuschemeng.6b01609.

\section{INTRODUCTION}

Over past few years, the society has become aware of their activities potential toxicity, both for the environment and for human health. One of these activities is related to pharmaceuticals and personal care products. Many cosmetic formulations contain substances as preservatives or additives which/that have an important environmental impact. Two classes of compounds used in suncare and body care cosmetics have potential oestrogenic and/or genotoxic properties: parabens and organic ultraviolet (UV) filters.

Parabens, p-hydroxybenzoic acid alkyl esters, are antimicrobial agents present in food, drugs, cosmetics, and toiletries. ${ }^{1}$ Because of their good stability, non-volatility and low cost, they are used commonly throughout the world and found in more than 13,200 formulations. ${ }^{2}$ Recent studies show the presence of parabens, also in combination with phthalates, in the majority of body care cosmetics analysed, including deodorants, creams and lotions.3,4 The antimicrobial activity increases with the alkyl group chain length from methyl to n-butyl so that combination of different parabens is the most frequently used preservative system. ${ }^{5}$ The European Union permits the use of parabens in cosmetic products with a maximum concentration of each one of $0.4 \mathrm{wt} \%$ and a total maximum concentration of 0.8wt\% (EU Cosmetics Directive 76/768/EEC). ${ }^{4}$ Some authors revealed that parabens are rapidly absorbed through intact skin. ${ }^{6-8}$ This effect can be influenced by their lipophilic character and the presence of penetration enhancers found in cosmetic preparations. For these reasons, they may be able to accumulate in fatty components of body tissues, what is called bioaccumulation. ${ }^{9}$ Several studies report the ability of parabens to disrupt physiologically important functions, both in vitro and in vivo essays. These disturbances can influence on breast cancers, male reproductive functions and the development of malignant melanomas among others. ${ }^{4,10,11}$ Therefore, new restrictions respect to parabens uses are impacting to health industries since last few years and the search for an effective substitute preservative is still a challenge.

Thinking about alternative materials that present antimicrobial properties, $\mathrm{Ag}$ and $\mathrm{ZnO}$ seem the most solid promises. Ag is presented as a strong candidate due to its use to control bacterial growth in a variety of applications. ${ }^{12-16}$ Its principal characteristics are its effectiveness against a broad spectrum of 
E. de Lucas-Gil, F. Rubio-Marcos, P. Leret, B. Motos-Pérez, M. Monte-Serrano, J. Menéndez, J.F. Fernández, Opening a New Gate to Glass Preservative with Long-Lasting Antimicrobial Activity as Replacement of Parabens, ACS Sustain. Chem. Eng. 5 (2017) $294-302$. doi:10.1021/acssuschemeng.6b01609.

microorganisms, hard skin penetration and low cytotoxicity. Nevertheless, it is necessary to study the behaviour of Ag because some Ag-based compounds gradually precipitate in solutions and physically separate from cosmetic components, compromising its antimicrobial effects. ${ }^{17} \mathrm{ZnO}$ appears promising because of its high antimicrobial activity, ${ }^{18,19}$ low toxicity, and easy clearance. ${ }^{20}$ However, there are few and contradictory specific studies regarding antimicrobial efficacy of $\mathrm{ZnO}$ in the context of topical product preservation.

UV filters are present in cosmetic sunscreen products. Their principal activity is to block the sunlight UV radiation in order to protect skin from their harmful effects. In sunscreen formulations the most commonly used organic UV filters are $p$-aminobenzoic acid (PABA) and its derivatives, avobenzone (AVB), benzophenone compounds (Bp), benzylidene camphor derivatives (BC) and octyl methoxycinnamate (OMC). ${ }^{21}$ The European Union regulates the limits of UV filters that may be added to other products (Council Directive 76/768/EEC). The UV filters are at most $10 \mathrm{wt} \%$ of the formulation: 10wt \% for octyl methoxycinnamate (OMC) and benzophenone-3 (Bp-3), 8wt\% for octyldimethyl-PABA (OD-PABA) and $4 \mathrm{wt} \%$ for 4 -methylbenzylidene camphor (4-MBC). ${ }^{1}$ Organic UV filters are relevant contaminants able to bioaccumulate in the environment due to their highly lipophilic character. Furthermore, studies show that organic UV filters are toxic to algae, crustaceous and corals.22,23 Respect to toxicology in humans, they can be exposed to bioaccumulation by dermal absorption or through the food chain..$^{24}$ Moreover, recent studies reveal that several organic UV filters affect human health, highlighting oestrogenic and anti-androgenic activities ${ }^{1,24,25}$ and photoallergic contact dermatitis. ${ }^{21,24,26}$ Such is the concern about the potential toxicology of organic UV filters that Schlumpf et al. ${ }^{24}$ propose necessary to consider the drawbacks of extensive organic UV screen use from both a medical and an ecological perspective. As mentioned for parabens preservatives, new UV blocking compounds are demanded without the potential risks of the actual organic UV filters.

Nowadays, new routes are investigated employing inorganic UV filters. There are two inorganic UV filters: titanium dioxide $\left(\mathrm{TiO}_{2}\right)$ and zinc oxide $(\mathrm{ZnO})$ particles. These filters are chemically and biologically inert and are unlikely to cause irritation or skin sensitization. ${ }^{26}$ One of the properties that make cytotoxic particles is size because they could penetrate or alter the skin. In the case of $\mathrm{ZnO}$, there 
E. de Lucas-Gil, F. Rubio-Marcos, P. Leret, B. Motos-Pérez, M. Monte-Serrano, J. Menéndez, J.F. Fernández, Opening a New Gate to Glass Preservative with Long-Lasting Antimicrobial Activity as Replacement of Parabens, ACS Sustain. Chem. Eng. 5 (2017) $294-302$. doi:10.1021/acssuschemeng.6b01609.

is no clear evidences about nanoparticles permeation across the skin barrier. ${ }^{27,28}$ As regards $\mathrm{TiO}_{2}$, nanoparticles between 4 and $60 \mathrm{~nm}$ could penetrate skin layer. ${ }^{29}$ Mostly, inorganic UV filters are less probable to induce toxicity than organic ones. In this sense, the use of nano-free inorganic UV filters is a challenge for sunscreens.

In this work, we provide an inorganic composite with preservative and UV filter functions as an alternative to organic preservatives and UV filters. To compensate these properties, we combine nanofree inorganic elements that present same characteristics such as $\mathrm{TiO}_{2}$ like $\mathrm{UV}$ filter and $\mathrm{Ag}$ and $\mathrm{ZnO}$ as antimicrobial agents. $\mathrm{TiO}_{2}$ is chosen because it does not cause photoallergy unlike organic ones and absorbs wide range of UV wavelength. The employment of antimicrobials Ag and $\mathrm{ZnO}$ can reduce the toxicity present on parabens while maintaining the preservative property. The behaviour of the combined action of these inorganic composites as UV filter and preservative material is reported for sunscreen case. This idea leads to develop the main aim of this study: low-cost production of "ecofriendly" material with sunlight UV radiation absorption and preservative properties. To that end, we develop a method for the controlled dispersion of inorganic UV filter on the surface of the new preservative through a cooperative assembly-directed process at room temperature. Thanks to its advantages such as reduction of material amount and production cost, manufacturing and ease of incorporation in different matrices, this inorganic composite can be used in a wide range of applications like personal care products, composite integrated in polymers, UV screen textile or coatings in outdoor environments.

\section{EXPERIMENTAL SECTION}

Syntheses of preservatives. Two preservatives based on different matrix were created: one with a clay matrix (R1) and other with a glass matrix (B4). The main physical and chemical characteristics are summarized in table S1. Clay preservative (R1) was synthesized as follows: bentonite clay was modified with 33 wt. $\%$ of hexadecyltrimethylammonium bromide $\left(\mathrm{C}_{19} \mathrm{H}_{42} \mathrm{BrN}\right)$. The mixture was dispersed in ethanol at room temperature using $1 \mathrm{~g}$ of modified clay per $100 \mathrm{~g}$ solvent. After that, $0.05 \mathrm{~g} \mathrm{AgNO}_{3}$ was added to the dispersion and was refluxed at $70^{\circ} \mathrm{C}$ for $6 \mathrm{~h}$. Then the dispersion was decanted, excess solvent removed and the clay was dried in a convection oven for $1 \mathrm{~h}$ at $70^{\circ} \mathrm{C}$. Glass preservative (B4) was synthesized with the following starting materials: 
E. de Lucas-Gil, F. Rubio-Marcos, P. Leret, B. Motos-Pérez, M. Monte-Serrano, J. Menéndez, J.F. Fernández, Opening a New Gate to Glass Preservative with Long-Lasting Antimicrobial Activity as Replacement of Parabens, ACS Sustain. Chem. Eng. 5 (2017) $294-302$. doi:10.1021/acssuschemeng.6b01609.

sodium hexametaphosphate, calcium oxide, boric acid, zinc oxide and silver oxide. In a typical preparation process, these materials were mixed using a ribbon blender. After that, the mixture was sieved to $200 \mu \mathrm{m}$ to remove agglomerates and melted in a smelter at $950^{\circ} \mathrm{C}$ for $4 \mathrm{~h}$. The liquid batch was cooled and cut into small crystals (3-4 mm) using a crusher. Finally, small crystals were grinded using a hammer mill and large particles were isolated in the cyclone.

Formation process of inorganic composites. These two preservatives R1 and B4 were combined separately with and inorganic UV filter based on $\mathrm{TiO}_{2}$ (ET). The formation of the ET UV-microcomposite was also previously described by using the dry-dispersion methodology. ${ }^{30}$ The use of dry-dispersion ensures both the stability of the glass preservative and the homogenous distribution in cosmetic preparation in spite of the low dose.

Sunscreen preparation. In a standard preparation, ingredients of the Fatty Phase, described in Table S2, are melted and heated to $80-85^{\circ} \mathrm{C}$ until completely solubilized. Separately, Aqueous Phase (ingredients are mentioned in Table S2) is heated to $80-85^{\circ} \mathrm{C}$ and UV filter or composite is added under stirring. Then, Fatty Phase is added into Aqueous Phase. Subsequently, the inorganic-organic mixture is cooled to $50^{\circ} \mathrm{C}$ while stirring. Reached that temperature, Benzyl Alcohol is added and cooling is completed. Ingredients and concentrations details are schematically shown in Supplementary Table 2.

Materials characterization. The Clay preservative (R1) and Glass preservative (B4) materials were fully characterized. Structural characterization was determined by X-ray Diffraction analysis (XRD), Fourier Transform Infrared Spectroscopy (FT-IR) and ${ }^{31} \mathrm{P}$ solid state Nuclear Magnetic Resonance (31P NMR). XRD was carried out using a X'Pert PRO Theta/2theta of Panalytical, Cu Ka radiation, PANalytical, The Netherlands. The patterns were recorded over the angular range $2-70^{\circ}(2 \theta)$ with a step size of $0.0334^{\circ}$ and a time per step of 100 seconds, using $\mathrm{Cu} \mathrm{Ka}$ radiation $(\lambda=0.154056 \mathrm{~nm})$ with working voltage and current of $40 \mathrm{kV}$ and $100 \mathrm{~mA}$, respectively. FT-IR spectra were measured using a Perkin Elmer Spectrum 100 with a wave number range from $400-4000 \mathrm{~cm}^{-1}$. 31P MAS (magic angle spinning) NMR (nuclear magnetic resonance) spectra were recorded on a Bruker AV-400WB spectrometer operating at $161.96 \mathrm{MHz}$. The pulse length was $2 \mu \mathrm{s}$ and $10 \mathrm{~s}$ delay time was used. Spinning rate of $10 \mathrm{kHz}$. Thermal characterization of glass preservative was resolved by Differential Thermal AnalysisThermogravimetric Analysis (DTA-TGA, Netzsch STA 409 C) and Heating Microscope (HMS, HR18 Hesse Instruments). DTA-TGA curves were recorded over the temperature range $25-950^{\circ} \mathrm{C}$ with a heating rate of $3^{\circ} \mathrm{C}$ $\min ^{-1}$ and a flow rate of $0.04 \mathrm{~L} \mathrm{~min}^{-1}$ under an air atmosphere, respectively. Particle size distribution of materials was evaluated by Dynamic Light Scattering (DLS) with Mastersizer S equipment (Malvern). 
E. de Lucas-Gil, F. Rubio-Marcos, P. Leret, B. Motos-Pérez, M. Monte-Serrano, J. Menéndez, J.F. Fernández, Opening a New Gate to Glass Preservative with Long-Lasting Antimicrobial Activity as Replacement of Parabens, ACS Sustain. Chem. Eng. 5 (2017) $294-302$. doi:10.1021/acssuschemeng.6b01609.

Electron Microscopy. The morphology of the powders was evaluated using primary electrons images of field emission scanning electron microscopy (FE-SEM, Hitachi S-4700). The composition of the commercial products was estimated using Energy Dispersive Spectroscopy, EDS. The average particle size was determined from FESEM micrographs by an image processing and analysis program (Leica Qwin, Leica Microsystems Ltd, Cambridge, England) considering more than 200 particles in each measurement.

Challenge Test. The challenge test is a conservation essay designed by standard NF EN ISO 11930 to evaluate antimicrobial protection and/or microbiological risk of the preservative system in the model products. The product was inoculated with microorganisms at a concentration $10^{5-106} \mathrm{CFU} \mathrm{mL}^{-1}$ (colony forming units per $\mathrm{mL}$ of product) for bacteria and $10^{4-10^{5} \mathrm{CFU} \mathrm{mL}} \mathrm{mL}^{-1}$ for fungi. Five microorganisms were checked against for challenging the preservative system in a product. The test is carried out using the following microbial strains: Staphylococcus aureus (CECT 240, ATCC 6538P), Escherichia coli (CECT 516, ATCC 8739), Pseudomonas aeruginosa (CECT 110, ATCC 10145), Candida albicans (CECT 1394, ATCC 10231), Aspergillus brasiliensis (CECT 2807, ATCC 6275). The inoculated product was held at $24.5^{\circ} \mathrm{C}$ in the dark for 28 days. Aliquots at suitable time intervals are collected: just after product inoculation (T0), 7 days (T7), 14 days (T14) and 28 days (T28). Bacteria and fungi were recounted by Plate Count Agar (PCA) method. All tests were performed in duplicate.

Chemical Analysis. $\mathrm{Ag}^{+}$and $\mathrm{Zn}^{2+}$ released were determined by inductively coupled plasma atomic emission spectroscopy (ICP-AES, Iris Advantage, Thermo Jarrell Ash). For sample preparation, $10 \mathrm{~g} \mathrm{L^{-1 }}$ of product was added in $100 \mathrm{~mL}$ of distilled water. Aliquots at suitable time intervals are collected: just after product inoculation (T0), 7 days (T7), 14 days (T14) and 28 days (T28). The suspensions were centrifuged and decanted obtaining a colourless dissolution. Data are expressed in concentration (ppm) of each element and extrapolated from raw materials to sunscreen concentration.

\section{RESULTS AND DISCUSSION}

Who is who in the inorganic composite? The study has been realized with market available raw materials. We use two inorganics preservatives with different matrix, one based on clay and other based on glass. Both inorganic preservatives present $\mathrm{Ag}^{+}$like active principle and the second of them also has a contribution of $\mathrm{ZnO}$. As inorganic UV filters, we employ a microcomposite material whose principal component is silicon coated $\mathrm{TiO}_{2}$. The compositions and physicochemical properties of these commercial materials are shown in Supplementary Table 1. 
E. de Lucas-Gil, F. Rubio-Marcos, P. Leret, B. Motos-Pérez, M. Monte-Serrano, J. Menéndez, J.F. Fernández, Opening a New Gate to Glass Preservative with Long-Lasting Antimicrobial Activity as Replacement of Parabens, ACS Sustain. Chem. Eng. 5 (2017) $294-302$. doi:10.1021/acssuschemeng.6b01609.

For a better understanding about preservatives structure, X-Ray diffraction (XRD) is realized. Supplementary Fig. 1 shows the diffraction pattern of clay preservative (hereafter named as R1). It can be seen that all peaks correspond to a single phase, bentonite. Therefore, we can define that the main composition of the R1 matrix is bentonite clay. XRD diffractogram of glass preservative (henceforth referred to as B4) is plotted in Fig. 1a. This pattern displays the characteristic broad band of amorphous materials. However, the deconvolution shows two Gaussians under the curve (Fig. 1b). This can be associated to the existence of two glass-networks. In this regard the structural characterization of B4 preservative needs complementary analysis. Fourier Transform Infrared Spectroscopy (FT-IR), Fig. 1c, shows only important bands between $1400 \mathrm{~cm}^{-1}$ and $400 \mathrm{~cm}^{-1}$ wavenumber, typical of phosphate groups ${ }^{31}$. The strong band at $\sim 552 \mathrm{~cm}^{-1}$ is attributed to bending vibrations of bridging phosphorus, $\delta(\mathrm{O}-\mathrm{P}-\mathrm{O})$. The absorption band $\sim 738 \mathrm{~cm}^{-1}$ is assigned to symmetric stretch of phosphorus, $v_{\mathrm{s}}(\mathrm{P}-\mathrm{O}-\mathrm{P})$. As can be seen in the inset of Fig. 1c, the broad band at $1400-800 \mathrm{~cm}^{-1}$ is fitted to the sum of 6 Gaussians peaks. The band at $905 \mathrm{~cm}^{-1}$ may be attributed to asymmetric stretching vibration of metaphosphate chain, $\mathrm{vas}_{\mathrm{as}}\left(\mathrm{PO}_{2}{ }^{-}\right)_{\text {chain. }}{ }^{32}$ Meanwhile, at $985 \mathrm{~cm}^{-1}$ and $1033 \mathrm{~cm}^{-1}$ we can see bands corresponding to asymmetric stretching vibration of metaphosphate rings,

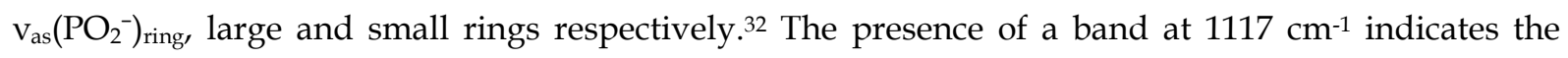
formation of terminal phosphate groups $\left(\mathrm{PO}^{2}{ }^{2-}\right)$. Thus, these band is assigned to asymmetric stretching vibration of pyrophosphates groups, $\mathrm{vas}_{\mathrm{as}}\left(\mathrm{PO}_{3^{2}}{ }^{2}\right) \cdot 32$ The absorption bands at $1172 \mathrm{~cm}^{-1}$ and $1248 \mathrm{~cm}^{-1}$ are assigned to symmetric $\left(\mathrm{v}_{\mathrm{s}}(\mathrm{P}=\mathrm{O})\right)$ and asymmetric $\left(\mathrm{v}_{\mathrm{as}}(\mathrm{P}=\mathrm{O})\right)$ stretching of doubly bonded oxygen vibration respectively. The range between 900 to $1050 \mathrm{~cm}^{-1}$ that belongs to metaphosphate groups, it is associated to $\mathrm{Q}^{2}$ phosphorus environment, while range about $1100 \mathrm{~cm}^{-1}$ of pyrophosphates groups is related to $\mathrm{Q}^{1}$ environment. Therefore, the analysis of IR spectra reveals the breakdown of the ring type structures $\left(\mathrm{Q}^{2}\right)$ to into small chains and terminal phosphate groups $\left(\mathrm{Q}^{1}\right)$. Once it is known the presence of phosphates, the ${ }^{31} \mathrm{P}$ MAS NMR studies reveals which species dominate the structure of the glasses preservative. As can be seen in Fig 1d, a main signal is revealed at $-10 \mathrm{ppm}$. This band is formed from three Gaussian peaks. Each peak can be assigned to phosphorus atoms sites: $\mathrm{Q}^{0}(-2.2 \mathrm{ppm} ; 26 \%), \mathrm{Q}^{1}(-10.1 \mathrm{ppm} ; 69 \%)$ and $\mathrm{Q}^{2}(-18.5 \mathrm{ppm} ; 5 \%)$ of electronic phosphorus environments. As we have seen in FTIR, the increased presence of $\mathrm{Q}^{1}$ indicates the breaking of the 
E. de Lucas-Gil, F. Rubio-Marcos, P. Leret, B. Motos-Pérez, M. Monte-Serrano, J. Menéndez, J.F. Fernández, Opening a New Gate to Glass Preservative with Long-Lasting Antimicrobial Activity as Replacement of Parabens, ACS Sustain. Chem. Eng. 5 (2017) $294-302$. doi:10.1021/acssuschemeng.6b01609.

rings hexametaphosphate $\left(\mathrm{Q}^{2}\right.$ only) to pyrophosphate $\left(\mathrm{Q}^{1}-\mathrm{Q}^{1}\right)$, phosphate chains $\left(\mathrm{Q}^{2}\right.$ middle groups with $\mathrm{Q}^{1}$ end groups) or orthophosphate groups $\left(\mathrm{Q}^{0}\right) \cdot{ }^{33}$ Nevertheless, the signal position is not only dependent on the type of $\mathrm{Q}^{\mathrm{n}}$ group; it also depends on the neighbouring atoms. As we mentioned, $\mathrm{ZnO}$ and $\mathrm{Ag}$ are introduced in glass matrix of $\mathrm{B} 4$ preservative to confer it antimicrobial properties. The introduction of these cations, which can exchange with $\mathrm{Na}$ and $\mathrm{Ca}$ cations of the matrix, can influence on its chemical shifts. About Ag, a NMR study reveals that the phosphate network was unaltered by exchanging sodium with silver for up to one quarter of the initial sodium content. ${ }^{34}$ Likewise, zinc can replace sodium or calcium cation causes changes in phosphate networks. ${ }^{35}$ These changes can be observed in ${ }^{31}$ P MAS NMR, moving peaks to a more negative chemical shift as the phosphate counter-ion was replaced by the zinc. This is caused by difference between the cation potential (charge to radius ratio) of $\mathrm{Zn}$ and $\mathrm{Na}$ or $\mathrm{Ca}$; as the cation potential of the modifying cation increases, the phosphorus chemical shift becomes more negative. ${ }^{36}$ The observation of zinc in the network by displacement of ${ }^{31 P}$ NMR chemical shift is in good agreement with the XRD study in which two glass-networks are observed. These two networks are one Na-rich and other Zn-rich. To complete B4 preservative study, a thermal characterization is realized. TGA (Fig. 1e, red curve), shows a $0.5 \%$ total weight loss, where are emphasized two important ranges, from 50 to $205^{\circ} \mathrm{C}$ and from 205 to $410^{\circ} \mathrm{C}$, which are marked as I and II. Both of them are ascribed as dehydration processes, the range I corresponds to the loss of adsorbed water while, range II is associated with the loss of lattice water. This small weight loss indicates that water presents in B4 preservative is practically non-existent, which is in conjunction with the non-presence of O-H bands in FTIR. The DTA curve (Fig. 1e, blue curve) is characterized by two exothermic peaks, the first from 400 to $560^{\circ} \mathrm{C}$ and the second one around $625^{\circ} \mathrm{C}$. Heating Microscope (HMS) analysis (Fig. 1f) is utilized to assist in the DTA bands identification. At RT (Fig. 1f-1), the shape and area of B4 observed in picture 1 is set as reference. From $350^{\circ} \mathrm{C}$, we can see a decrease of the area being created a deformation point at $394^{\circ} \mathrm{C}$ (Fig. $\mathbf{1 f}-2$ ). After that, area continues to decline and at $460^{\circ} \mathrm{C}$ (Fig. 1f-3) an important change in shape happens, being a sphere. This sphere shape indicates the glass transition temperature $\left(\mathrm{T}_{\mathrm{g}}\right)$ of $\mathrm{B} 4$ preservative that closely relates with DTA broad band at $460^{\circ} \mathrm{C}$. The fact that this band has a broad range of temperature, from 400 to $560^{\circ} \mathrm{C}$, agrees with a multiphase phosphate glass with different $\mathrm{T}_{\mathrm{g}}$. Then, at $612^{\circ} \mathrm{C}$ (Fig. 1f-4) 
E. de Lucas-Gil, F. Rubio-Marcos, P. Leret, B. Motos-Pérez, M. Monte-Serrano, J. Menéndez, J.F. Fernández, Opening a New Gate to Glass Preservative with Long-Lasting Antimicrobial Activity as Replacement of Parabens, ACS Sustain. Chem. Eng. 5 (2017) $294-302$. doi:10.1021/acssuschemeng.6b01609.

hemisphere point is located without area change. Finally, the flow point is observed at $632^{\circ} \mathrm{C}$ (Fig. 1f-

5) which leads to the total area decrease. This point is clearly related to melting point so that DTA peak around $625^{\circ} \mathrm{C}$ is the melting point temperature $\left(T_{m}\right)$ of $B 4$ preservative.
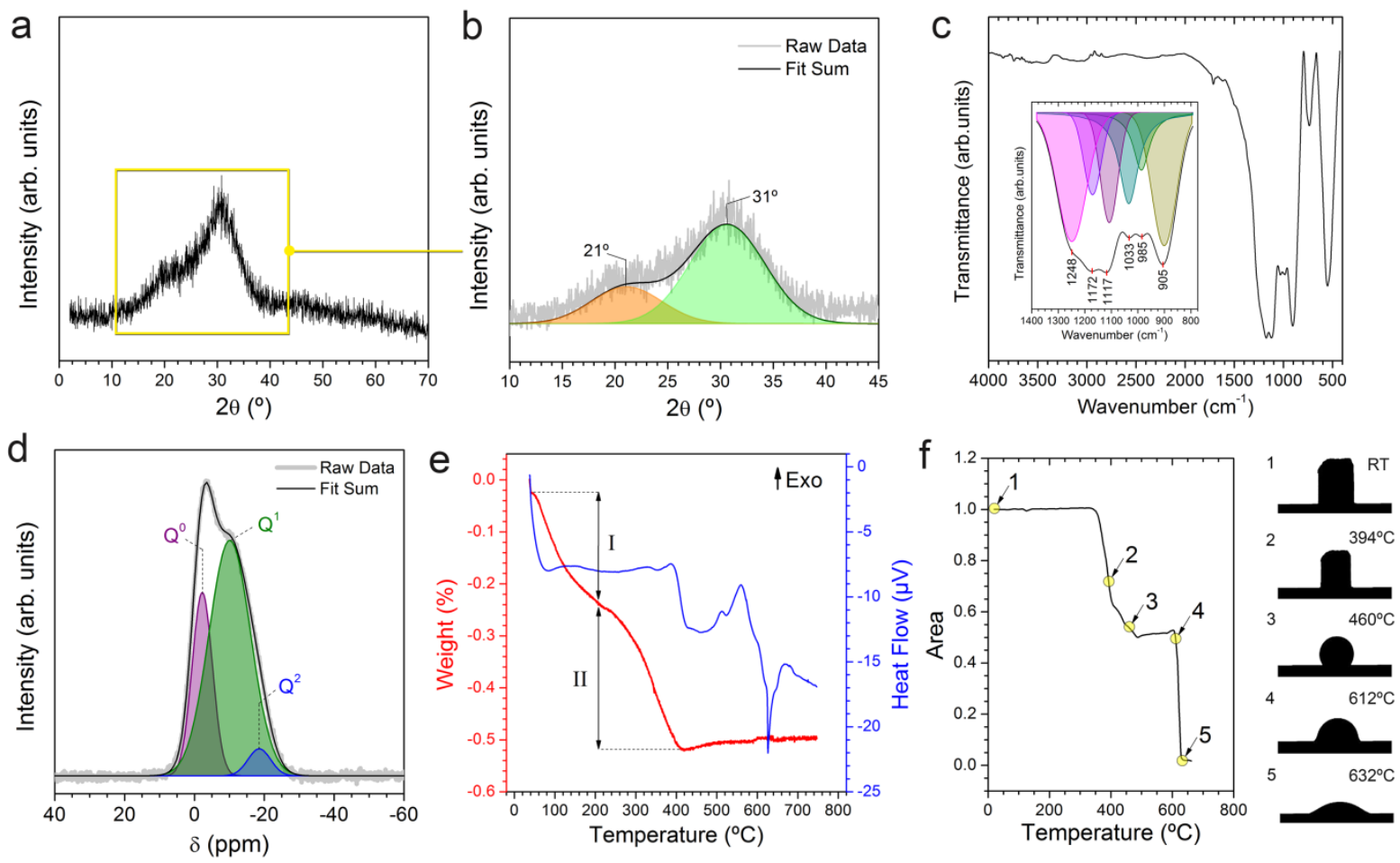

Figure 1 | Structural characterization B4 glass preservative. XRD diffractogram (a) displays a typical broad band of amorphous material. The panel $\mathbf{b}$ shows the deconvolution of glass preservative curve. FTIR spectrum (c) presents usual bands of phosphate group. The FTIR inset corresponds to the deconvolution of 5 hidden peaks in broad band between 1400 and $800 \mathrm{~cm}^{-1}$. ${ }^{31} \mathrm{P}$ MAS NMR spectrum (d) fitted to the sum of three Gaussians peaks, which are indexed as $\mathrm{Q}^{0}, \mathrm{Q}^{1}$ and $\mathrm{Q}^{2}$ phosphorus environments, respectively. The panel e displays TGA (red) and DTA (blue) with two important endothermic peaks corresponding to $\mathrm{T}_{\mathrm{g}}$ and $\mathrm{T}_{\mathrm{m}}$, respectively. The panel $\mathbf{f}$ shows HMS, area $v s$. temperature graph and pictures taken at main sample changes during analysis (from 1 to 5 ).

The morphology of the materials is shown in field emission scanning electron microscopy (FE-SEM) micrographs, Fig. 2. Preservative based on bentonite clay (R1), represented in Fig. 2a-b, presents agglomerates with predominantly spherical shapes and sizes below $10 \mu \mathrm{m}$. At higher magnifications (Fig. 2b), it is observed that these agglomerates are made of layered shaped primary particles having $500 \mathrm{~nm}$ in diameter. The second preservative under study is a powdered glass shown in Fig 2c-d. First differences can be seen in the agglomerate shapes. Preservative powdered glass (B4) agglomerates are disorganized in size and structure and no preferential growing pattern is observed. Sizes vary 
E. de Lucas-Gil, F. Rubio-Marcos, P. Leret, B. Motos-Pérez, M. Monte-Serrano, J. Menéndez, J.F. Fernández, Opening a New Gate to Glass Preservative with Long-Lasting Antimicrobial Activity as Replacement of Parabens, ACS Sustain. Chem. Eng. 5 (2017) $294-302$. doi:10.1021/acssuschemeng.6b01609.

between $1 \mu \mathrm{m}$ to $10 \mu \mathrm{m}$. A keen observation (Fig. 2d) shows particles having irregular surfaces characteristic of glass fracture with mirror planes. Inorganic UV filter (ET), see Fig. 2e-f, is formed by $\mathrm{TiO}_{2}$ agglomerates. Principal shapes of these agglomerates are spheres-like composites with diameters about $5 \mu \mathrm{m}$. From high-resolution scanning electron microscope (HR-SEM) image (Fig. 2f), we can see nanoparticles with ca. $30 \mathrm{~nm}$ anchored on $200 \mathrm{~nm}$ submicronic particles. The fact is that these nanoparticles are strongly bonded making a non-nanometric composite that behaves as a microparticle. ${ }^{30}$
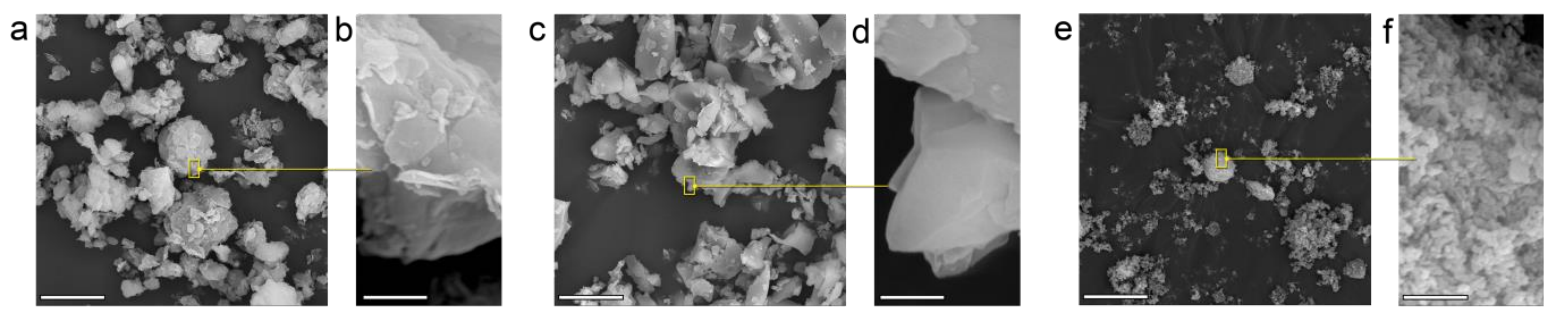

Figure 2 | Morphological characterization of primary materials: inorganic preservatives and inorganic UV filter. The panels $\mathbf{a}$ and $\mathbf{b}$ show the micrographs of R1 preservative. The other preservative, B4 preservative, is represented in panels $\mathbf{c}$ and $\mathbf{d}$. The last panels, e and $\mathbf{f}$, correspond to ET UV filter based on $\mathrm{TiO}_{2}$. Scale bar of low-resolution scanning electron microscope, LRSEM, (a, c, e) is $10 \mu \mathrm{m}$ and high-resolution scanning electron microscope, HR-SEM, (b, d, f) is $500 \mathrm{~nm}$.

A single dispersion process: two scenarios. For a better integration of these inorganic compounds, we propose a dry mixture of them, which allows providing ET UV filter as the major component and just $0.1 \mathrm{wt} \%$ of preservative. The expected behaviour of dispersion is that ET UV filter partially coats the preservatives, $\mathrm{R} 1$ or $\mathrm{B} 4$, following the dry dispersed procedure ${ }^{37-39}$ at room temperature (RT). The dry process consisted on shaking R1 or B4 preservative/ET UV filter mixtures and $1 \mathrm{~mm} \mathrm{ZrO}_{2}$ balls in a 60 $\mathrm{cm}^{3}$ nylon container for $5 \mathrm{~min}$ at $50 \mathrm{rpm}$ using a tubular-type mixer. Pure preservatives and ET UV filter powders were also subject to the same mixing process to ensure that no structural disorder contributions were produced by the mixing process. Two new composites are obtained, one composed by ET UV filter and R1 preservative (sample hereafter named as R1/ET) and the other one integrated by ET UV filter and B4 preservative (sample henceforth referred to as B4/ET).

In order to clarify the dispersion state of the ET UV filter and preservatives, FE-SEM characterization has been carried out on the R1/ET and B4/ET products. The micrographs presented in Fig. 3a-b, illustrate the structure of the R1/ET composite. The principal morphology, that it can be observed in 
E. de Lucas-Gil, F. Rubio-Marcos, P. Leret, B. Motos-Pérez, M. Monte-Serrano, J. Menéndez, J.F. Fernández, Opening a New Gate to Glass Preservative with Long-Lasting Antimicrobial Activity as Replacement of Parabens, ACS Sustain. Chem. Eng. 5 (2017) $294-302$. doi:10.1021/acssuschemeng.6b01609.

Fig. 3a, is spherical agglomerates with size about $5 \mu \mathrm{m}$. This kind of agglomerate reminds the morphology of the UV filter. However, a closer observation (Fig. 3b) allows us to discover platelets on the surface similar to those seen for R1 preservative. The nanoparticles agglomerates of ET UV filter remained anchored after the dispersing process; unlike the R1 preservative raw material dispersion. In the R1/ET composite, ET UV filter aggregates favour the deposition of clay platelets on their surface, which is completely and uniformly covered by the clay. In summary, R1/ET consists in spheres of hierarchically organized nanoparticles-microparticles coated by clay platelets, creating a core-shelltype structure.

On the other hand, the micrographs corresponding to B4/ET composite are shown in Fig. 3c-d. First, glass plate morphologies are predominant and corresponding to B4 preservative, as can be seen in Fig. 3c. If we observe in detail (Fig. 3d) ET nano-microparticles are anchored on plate surface. In this particular case, nanoparticles aggregates of UV filter are separated. B4/ET composite consists in ET UV filter small aggregates supported on glass plates. Under micrographs, EDS mapping of two dispersion products are represented (Fig. 3e-f). Fig. 3e shows the main elements of R1/ET composite: $\mathrm{Si}$, as major component of silicates typical of clay and as coating of ET UV filter, plus Mg like a cation. In addition, $\mathrm{Ag}$, active principle of $\mathrm{R} 1$ preservative, is distributed throughout the agglomerate. Respect to the Ti element, present in ET UV filter, is uniformly dispersed on the mixture. Main elements of B4/ET composite (Fig. 3f) are: P that composes phosphates representative of glass and $\mathrm{Na}$ like counter-ion. Their active ingredients, $\mathrm{Ag}$ and $\mathrm{Zn}$, are found throughout the sample. As in the previous case, Ti from the ET UV filter is disseminated on the glass plates.

To sum up, in R1/ET complex the hierarchically organized nanoparticles of the ET UV filter are surrounded by platelets of clay; meanwhile the main feature of the B4/ET composite is the high dispersion of ET UV filter small aggregates on the B4-glass plates surface. These two composites deliver different scenarios for antimicrobial activity studies on a sunscreen. 
E. de Lucas-Gil, F. Rubio-Marcos, P. Leret, B. Motos-Pérez, M. Monte-Serrano, J. Menéndez, J.F. Fernández, Opening a New Gate to Glass Preservative with Long-Lasting Antimicrobial Activity as Replacement of Parabens, ACS Sustain. Chem. Eng. 5 (2017) $294-302$. doi:10.1021/acssuschemeng.6b01609.
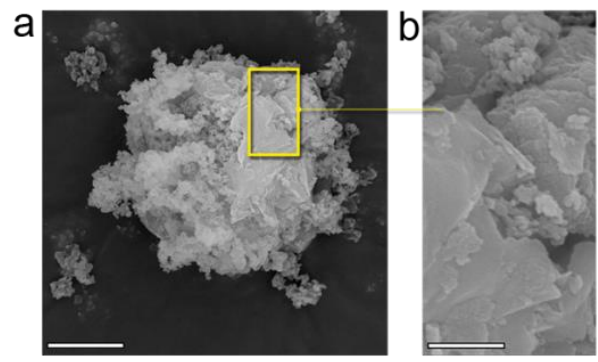

e
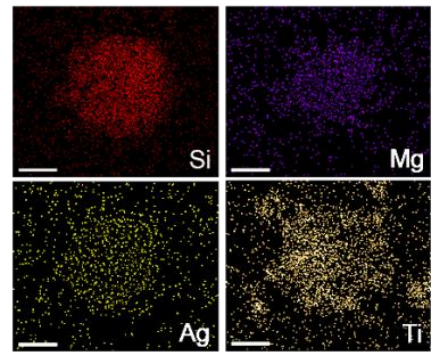

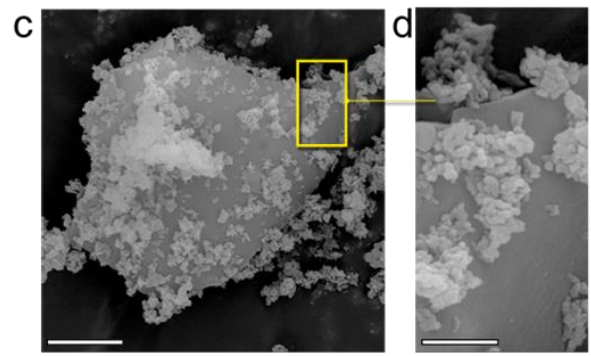

f
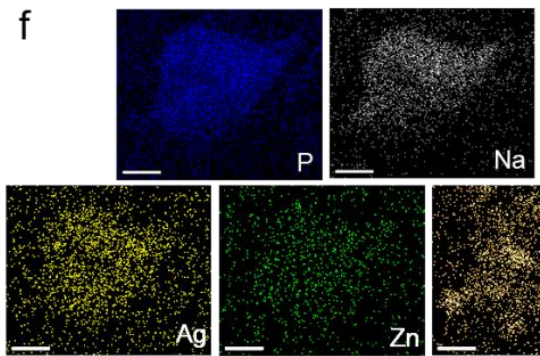

$\mathrm{Zn}$

Figure 3 | Dispersions of $\mathbf{0 . 1 \%}$ of inorganic preservatives (R1 and B4) on ET UV filter and their composition including principal elements and active ingredients. The micrographs of R1/ET composite $(\mathbf{a}, \mathbf{b})$ show spherical type agglomerates covered by layered clay particles. On the other hand, the principal morphology of B4/ET composite (c, d) is made of irregular glass plates with small $\mathrm{TiO}_{2}$ aggregates deposited on its surface. The EDS mapping of R1/ET (panels e) corresponds to micrograph a) and the one of B4/ET (panels $\mathbf{f}$ ) to image c. In addition, the principal composition of R1 preservative (e) is Si and $\mathrm{Mg}$ and $\mathrm{Ag}$ like active ingredient. B4 preservative (f) is mainly composed by $\mathrm{P}, \mathrm{Na}$ and $\mathrm{Ag}$ and $\mathrm{Zn}$ like active ingredients. In both cases, the presence of Ti corresponds to the ET UV filter. LR-SEM (a, c) and composition mapping (e, f) scale bar is $2 \mu \mathrm{m}$. Scale bar of HR-SEM insets (b, d) is $500 \mathrm{~nm}$.

Two are better than one: Finding a potential technological application of the inorganic composites.

One of the most important preservative functions is to kill or to prevent the growth of microorganisms over a relatively long period. The antimicrobial activity of samples is evaluated by the Challenge Test (NF EN ISO 11930). This assay consists of a conservation test designed to assess the antimicrobial protection of the preservative system in the model products. ${ }^{40}$ The microorganisms used in this study are Staphylococcus aureus (Gram-positive bacteria), Escherichia coli and Pseudomonas aeruginosa (Gramnegative bacteria), Candida albicans (yeast-like fungi) and Aspergillus brasiliensis (previously called Aspergillus niger, mould-like fungi). Three sunscreens are prepared without paraben preservatives and correspond to ET UV filter (used as a reference), R1/ET and B4/ET composites, respectively. The experimental details of sunscreen preparation are described in Methods section and Supplementary

Table 2. To that end, both composites R1/ET and B4/ET are added on aqueous phase under stirring and at $80-85^{\circ} \mathrm{C}$. Then, fatty phase is adding to aqueous phase with the composite to form inorganicorganic sunscreen. The samples are evaluated after suitable time intervals: just after product 
E. de Lucas-Gil, F. Rubio-Marcos, P. Leret, B. Motos-Pérez, M. Monte-Serrano, J. Menéndez, J.F. Fernández, Opening a New Gate to Glass Preservative with Long-Lasting Antimicrobial Activity as Replacement of Parabens, ACS Sustain. Chem. Eng. 5 (2017) $294-302$. doi:10.1021/acssuschemeng.6b01609.

inoculation (T0), 7 days (T7), 14 days (T14) and 28 days (T28). Fig. 4 displays the evaluation of global preservative efficacy in each formulation sunscreen. The results against bacteria E. coli and S. aureus (Fig. 4a-b) show an effectiveness of the preservative system satisfactory for all types of compositions. The effectiveness of the ET UV filter is surprisingly because for these bacteria the Challenge Test shown a good inhibition in spite to the absence of paraben additions. The behaviour against the other bacterium $P$. aeruginosa varies for each product, see Fig. 4c. Sunscreen with ET UV filter does not inhibit growth of it, thus the bacterial population finally exceeded the control. Product with R1/ET composite undergoes regrowth at 28 days, so that preservative is not effective enough. However, the B4/ET composition decreases bacterial growth even below detection limit after 7 days and keep it over time. Concerning C. albicans (Fig. 4d), an increase of population respect to the control is observed for ET and R1/ET based sunscreens. Conversely, B4/ET formulation reduces the fungus growth so it is effective over the time studied. For A. brasiliensis (Fig. 4e), ET UV filter and R1/ET compositions present similar behaviour. In ET UV filter sunscreen, population increases after 7 days, then a decrease of it is observed and finally proliferates at 28 days. Regarding R1/ET sunscreen, the composite reduces the fungus growth until 14 days to regrow after. The fungus growth variation suggests that two products are unstable preservatives. B4/ET based sunscreen reduces gradually population and remains active over time. This excellent antimicrobial behaviour of B4/ET based sunscreen can be seen in a visual comparison of Petri dish between microorganism populations at T0 and T28 (Supplementary Fig. 2). The products evaluation, according to the criteria A and B of the NF EN ISO 11930 standard (see Supplementary Table 3), is shown in Fig $\mathbf{4 f - j}$. These criteria require a minimum logarithmic reduction of microorganism population over time. Respect to ET and R1/ET compositions only meet criteria for E. coli and S. aureus at 28 days (Fig 4f-g). On the contrary, B4/ET based sunscreen meets the requirement of criteria after 28 days allowing it to be a promising preservative candidate. 
E. de Lucas-Gil, F. Rubio-Marcos, P. Leret, B. Motos-Pérez, M. Monte-Serrano, J. Menéndez, J.F. Fernández, Opening a New Gate to Glass Preservative with Long-Lasting Antimicrobial Activity as Replacement of Parabens, ACS Sustain. Chem. Eng. 5 (2017) $294-302$. doi:10.1021/acssuschemeng.6b01609.

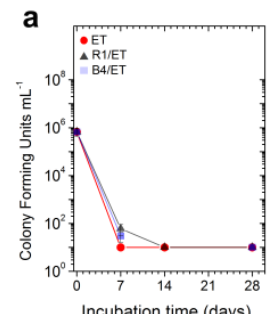

$\mathbf{f}$

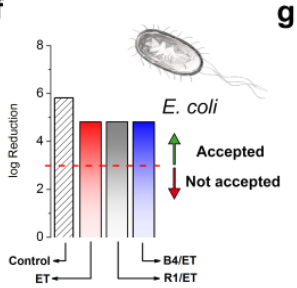

b

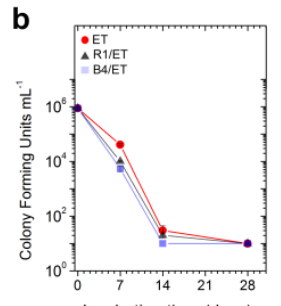

g

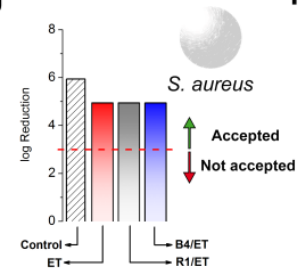

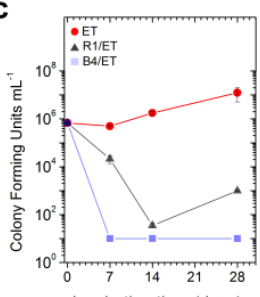



d

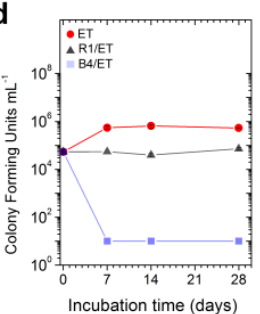

i

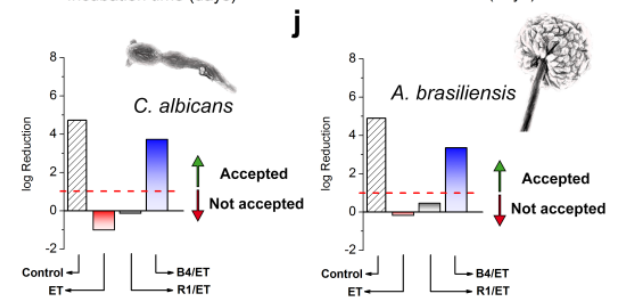

Figure 4 | Evolution of antibacterial and antifungal activity over 28 days in sunscreen prepared (Challenge Test). Bacterial growth of Escherichia coli (a), Staphylococcus aureus (b), Pseudomonas aeruginosa (c) and fungal growth of Candida albicans (d), Aspergillus brasiliensis (e) in the presence of ET (red), R1/ET (grey) and B4/ET (blue) sunscreens. The panels $\mathbf{f}, \mathbf{g}, \mathbf{h}, \mathbf{i}, \mathbf{j}$ represent logarithmic reduction of antimicrobial growth at 28 days. First bar (Control) represents initial logarithmic concentration of microorganism. Red dash line corresponds to criteria described on NF EN ISO 11930 (Supplementary Table 3). Data above the red dash line meet the criteria of the standard and data below it not meet the criteria. The mean and s.d. from three experiments is shown.

In order to understand the influence of active ingredients in antimicrobial activity, an assay of release in water is studied by ICP-AES, see Fig. 5. The R1 preservative contains only $\mathrm{Ag}^{+}$like principal antimicrobial agent. Fig. 5a shows that the tendency of this element is release completely in short times of 7 days. However, the behaviour of B4 preservative leaching is completely different, as can be seen in Fig. 5b. The principal antimicrobial agents of $\mathrm{B} 4$ preservative are $\mathrm{Ag}^{+}$and $\mathrm{Zn}^{2+}, \mathrm{which}^{2}$ concentrations available are higher than in R1 preservative. The $\mathrm{Ag}^{+}$releases more slowly from B4 than Ag cation of R1 preservative, reaching up to 14 days, possibly due to ET UV filter coating over B4 preservative. In addition, the presence of $\mathrm{Zn}^{2+}$ in water starts to increase after 14 days and continues over time. 
E. de Lucas-Gil, F. Rubio-Marcos, P. Leret, B. Motos-Pérez, M. Monte-Serrano, J. Menéndez, J.F. Fernández, Opening a New Gate to Glass Preservative with Long-Lasting Antimicrobial Activity as Replacement of Parabens, ACS Sustain. Chem. Eng. 5 (2017) $294-302$. doi:10.1021/acssuschemeng.6b01609.
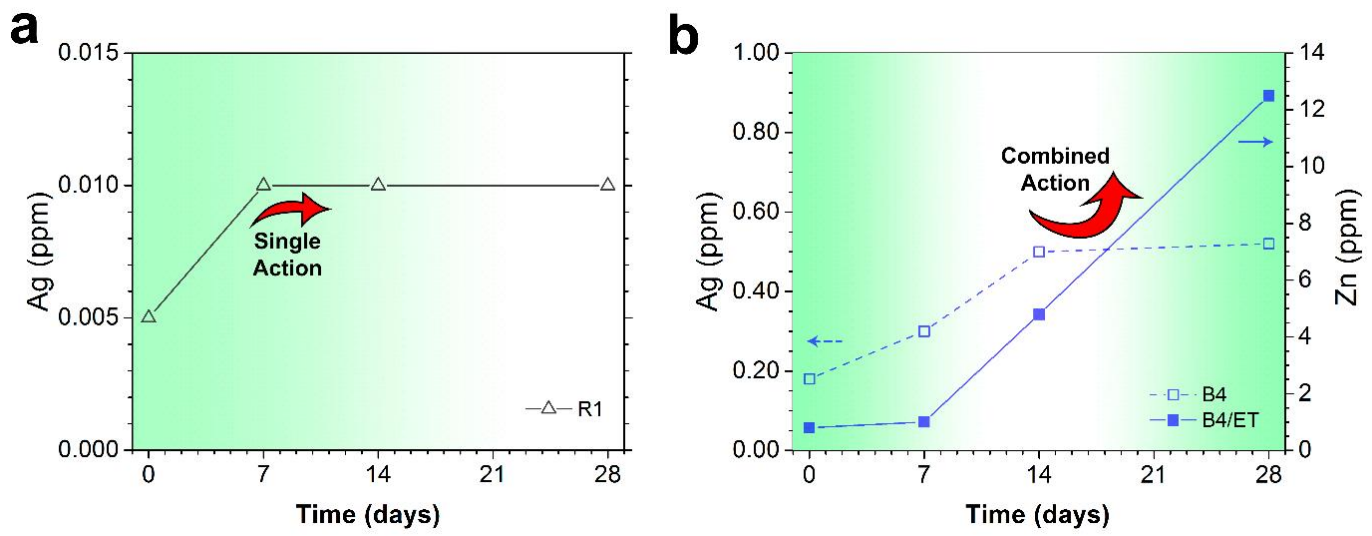

Figure 5 | Chemical analysis of active ingredients released in distilled water over time. The graphic a shows concentration of $\mathrm{Ag}+$ released corresponding to R1 preservative (empty grey triangle). The panel $\mathbf{b}$ displays the leaching behaviour of $\mathrm{Ag}^{+}$and $\mathrm{Zn}^{2+}$ concentrations found in B4 preservative (empty blue square) and the mixture with ET UV filter (filled blue square). Data are extrapolated from raw materials to sunscreen concentration. Detection limit: 0.005 ppm.

To check if the R1/ET and B4/ET composites maintain the UV filter behaviour of the ET filter raw material, the SPF (Sun Protection Factor) study of both products was performed and detailed in Supplementary Fig. 3. The results of the study reveal that in both products, the UV filter behaviour is retained without interfering in the preservative functionality.

To propose an exceptional candidate as a parabens substitute, is necessary a strong and long-lasting preservative properties. Mainly, the occurrence of antimicrobial activity is associated to cation release effects for inorganic compounds. In the R1/ET composite case, Fig. 5a shows a quick release of $\mathrm{Ag}^{+}$. This short $\mathrm{Ag}^{+}$leaching affects to common bacteria such as E. coli and S. aureus (grey line of Fig. 4a-b). However, a very resistant bacterium like $P$. aeruginosa increases the colony after 14 days (grey line of Fig. 4c). Respect to antifungal activity of $\mathrm{Ag}^{+}$shown in Fig. 4d-e (grey line), no growth inhibition is observed for R1/ET composite. Thus, Ag cation is effective in short times against common bacteria but it doesn't present activity against resistant bacteria and fungi. Conversely, B4/ET composite adds $\mathrm{Zn}$ cations in its composition besides $\mathrm{Ag}^{+}$. As already mentioned, both $\mathrm{Ag}$ and $\mathrm{Zn}$ cations are incorporated in the glass network forming new glass phases. Thanks to $\mathrm{Ag}^{+}$and $\mathrm{Zn}^{2+}$ leaching (Fig. $\mathbf{5 b}$ ) is possible to create an antimicrobial synergy between both cations. The $\mathrm{Ag}^{+}$is especially active against bacteria and $\mathrm{Zn}^{2+}$ fills the lack of antifungal activity of $\mathrm{Ag}$ cations. So, the antimicrobial activity of $\mathrm{Zn}$ cations is added to antibacterial activity of $\mathrm{Ag}^{+}$. This result is observed in Fig 4a-e (blue 
E. de Lucas-Gil, F. Rubio-Marcos, P. Leret, B. Motos-Pérez, M. Monte-Serrano, J. Menéndez, J.F. Fernández, Opening a New Gate to Glass Preservative with Long-Lasting Antimicrobial Activity as Replacement of Parabens, ACS Sustain. Chem. Eng. 5 (2017) $294-302$. doi:10.1021/acssuschemeng.6b01609.

line) where B4/ET based sunscreen inhibits the growth of microorganism, both bacteria and fungi. Therefore, B4/ET complies with the strong preservative property against common types of microorganisms. Additionally, the new interaction with glass network allows a controlled release of $\mathrm{Ag}^{+}$and $\mathrm{Zn}^{2+}$, see Fig. $\mathbf{5 b}$. This progressive leaching gives to B4/ET composite an extending activity in time, that is to say, the long-lasting antimicrobial property, as we have shown in Fig. 4.

\section{CONCLUSIONS}

To conclude, we have investigated a new inorganic UV filter and preservative composite based on $\mathrm{TiO}_{2}$, Ag and $\mathrm{ZnO}$. We propose that $\mathrm{B} 4$ inorganic preservative could replace cosmetic organic preservatives, such as parabens due to its less potential toxicity than organic ones. Besides, the ET filter composed by $\mathrm{TiO}_{2}$ is known by its excellent sunlight $\mathrm{UV}$ radiation absorbing properties. Herein, we have developed an inorganic UV filter aggregates on a new preservative surface called B4/ET composite, which yield an impressive antimicrobial activity. To evaluate the effectiveness about UV filter and preservative, sunscreens assays is realized. Challenge Test, used to known the antimicrobial capacity of the new product obtained, indicates excellent results according to criteria of the NF EN ISO 11930 standard. Moreover, the release of $\mathrm{Ag}^{+}$and $\mathrm{Zn}^{2+}$ is controlled by leaching experiments, which indicate a slow release of these cations over time thanks to the incorporation of $\mathrm{Zn}$ and Ag in phosphate network. For these two facts, we dare to propose that synergistic action between Ag-Zn cations is the key element for the long-lasting preservative properties of B4/ET composite. Furthermore, the new addition of B4 preservative on ET filter maintains the UV filter behaviour. Finally, it is worth noticing that the combination of ET filter and B4 preservative in one product allows reducing costs and required amount of material, improves the incorporation in different matrices and facilitates manufacturing. This enables a huge range of applications for this composite such as personal care products, composite integrated in polymers, UV screen textile or coatings in outdoor environments among others.

\section{ACKNOWLEDGEMENTS}

The authors express their thanks to the MINECO (Spain) project MAT2013-48009-C4-1-P for their financial support. Dr. F. Rubio-Marcos is also indebted to MINECO for a "Juan de la Cierva" contract (ref: JCI-2012-14521), which is co-financed with European Social Fund. Dr. P. Leret is also indebted to MINECO for a "Torres 
E. de Lucas-Gil, F. Rubio-Marcos, P. Leret, B. Motos-Pérez, M. Monte-Serrano, J. Menéndez, J.F. Fernández, Opening a New Gate to Glass Preservative with Long-Lasting Antimicrobial Activity as Replacement of Parabens, ACS Sustain. Chem. Eng. 5 (2017) $294-302$. doi:10.1021/acssuschemeng.6b01609.

Quevedo" contract (ref: PTQ-12-05470), which is co-financed with European Social Fund. Dr. B. Motos-Pérez is also indebted to MINECO for a "Torres Quevedo" contract. Finally, authors are grateful to Ismael Santamaria for his assistance in the preparation of the compositions, to Luis Contreras for thermal measurements and to $\mathrm{M}^{\mathrm{a}}$ José Velasco and Pilar Ortega for ICP-AES measurements.

\section{AUTHOR INFORMATION}

\section{Corresponding Authors}

* E. de Lucas-Gil. E-mail: elucas@icv.csic.es

* F. Rubio-Marcos E-mail: frmarcos@icv.csic.es

Competing financial interests: The authors declare competing financial interests. E. L-G., M. M-S. and J. M. are employees of NanoBioMatters Industries S.L. and P. L. and B. M-P. are employees of Advanced Dispersed Particles S.L. Patent application of the B4 preservative (WO2015091960-A1) is submitted by NanoBioMatters Industries S.L.

\section{ASSOCIATED CONTENT}

\section{Supporting Information}

The Supporting Information is available free of charge on the ACS Publications website

Structural characterization of R1 clay preservative; Evolution of microorganism growth against B4/ET composite; Chemical analysis of active ingredients released in distilled water over time; Sun Protection Factor (SPF) assay of composites; Chemical composition and physicochemical characteristics of each material; Sunscreen compositions in a standard process; Criteria of the Challenge Test describe in the NF EN ISO 11930. 
E. de Lucas-Gil, F. Rubio-Marcos, P. Leret, B. Motos-Pérez, M. Monte-Serrano, J. Menéndez, J.F. Fernández, Opening a New Gate to Glass Preservative with Long-Lasting Antimicrobial Activity as Replacement of Parabens, ACS Sustain. Chem. Eng. 5 (2017) $294-302$. doi:10.1021/acssuschemeng.6b01609.

\section{REFERENCES}

(1) Gomez, E.; Pillon, A.; Fenet, H.; Rosain, D.; Duchesne, M. J.; Nicolas, J. C.; Balaguer, P.; Casellas, C. Estrogenic activity of cosmetic components in reporter cell lines: Parabens, UV screens, and musks. J. Toxicol. Environ. Heal. A 2005, 68 (4), 239-251.

(2) Elder, R. L. Final Report on the Safety Assessment of Methylparaben, Ethylparaben, Propylparaben, and Butylparaben. Int. J. Toxicol. 1984, 3 (5), 147-209.

(3) Shen, H. Y.; Jiang, H. L.; Mao, H. L.; Pan, G.; Zhou, L.; Cao, Y. F. Simultaneous determination of seven phthalates and four parabens in cosmetic products using HPLC-DAD and GC-MS methods. J. Sep. Sci. 2007, 30 (1), 48-54.

(4) Darbre, P. D.; Harvey, P. W. Paraben esters: review of recent studies of endocrine toxicity, absorption, esterase and human exposure, and discussion of potential human health risks. J. Appl. Toxicol. 2008, 28 (5), 561-578.

(5) Soni, M. G.; Taylor, S. L.; Greenberg, N. A.; Burdock, G. A. Evaluation of the health aspects of methyl paraben: a review of the published literature. Food Chem. Toxicol. 2002, 40 (10), 1335-1373.

(6) Whitworth, C. W.; Jun, H. W. Influence of Polysorbate 20 and Sodium Cholate on Uptake of p-Hydroxybenzoates by the Frog, Rana pipiens. J. Pharm. Sci. 1973, 62 (11), 1890-1891.

(7) Fischmeister, I.; Hellgren, L.; Vincent, J. Infrared spectroscopy for tracing of topically applied ointment vehicles and active substances on healthy skin. Arch. Dermatological Res. 1975, 253 (1), 63-69.

(8) Komatsu, H.; Suzuki, M. Percutaneous Absorption of Butylparaben through Guinea Pig Skin In Vitro. J. Pharm. Sci. 1979, 68 (5), 596-598.

(9) Xue, J.; Sasaki, N.; Elangovan, M.; Diamond, G.; Kannan, K. Elevated Accumulation of Parabens and their Metabolites in Marine Mammals from the United States Coastal Waters. Environ. Sci. Technol. 2015, 151002094531007.

(10) Darbre, P. D.; Aljarrah, a.; Miller, W. R.; Coldham, N. G.; Sauer, M. J.; Pope, G. S. Concentrations of Parabens in human breast tumours. J. Appl. Toxicol. 2004, 24 (1), 5-13.

(11) Darbre, P. D.; Byford, J. R.; Shaw, L. E.; Horton, R. A.; Pope, G. S.; Sauer, M. J. Oestrogenic activity of isobutylparabenin vitro and in vivo. J. Appl. Toxicol. 2002, 22 (4), 219-226.

(12) Zhang, M.; Zhao, Y.; Yan, L.; Peltier, R.; Hui, W.; Yao, X.; Cui, Y.; Chen, X.; Sun, H.; Wang, Z. Interfacial Engineering of Bimetallic Ag/Pt Nanoparticles on Reduced Graphene Oxide Matrix for Enhanced Antimicrobial Activity. ACS Appl. Mater. Interfaces 2016, 8 (13), 8834-8840.

(13) Baker, C.; Pradhan, a; Pakstis, L.; Pochan, D. J.; Shah, S. I. Synthesis and antibacterial properties of silver nanoparticles. J. Nanosci. Nanotechnol. 2005, 5 (2), 244-249.

(14) Morones, J. R.; Elechiguerra, J. L.; Camacho, A.; Holt, K.; Kouri, J. B.; Ramírez, J. T.; Yacaman, M. J. The bactericidal effect of silver nanoparticles. Nanotechnology 2005, 16 (10), 2346-2353.

(15) Pal, S.; Tak, Y. K.; Song, J. M. Does the antibacterial activity of silver nanoparticles depend on the shape of the nanoparticle? A study of the gram-negative bacterium Escherichia coli. J. Biol. Chem. 2015, 290 (42), 1712-1720.

(16) Sondi, I.; Salopek-Sondi, B. Silver nanoparticles as antimicrobial agent: A case study on E. coli as a model for Gramnegative bacteria. J. Colloid Interface Sci. 2004, 275 (1), 177-182.

(17) Kokura, S.; Handa, O.; Takagi, T.; Ishikawa, T.; Naito, Y.; Yoshikawa, T. Silver nanoparticles as a safe preservative for use in cosmetics. Nanomedicine 2010, 6 (4), 570-574.

(18) Zhong, Z.; Xu, Z.; Sheng, T.; Yao, J.; Xing, W.; Wang, Y. Unusual Air Filters with Ultrahigh Efficiency and Antibacterial Functionality Enabled by ZnO Nanorods. ACS Appl. Mater. Interfaces 2015, 7 (38), 21538-21544.

(19) Cai, Q.; Gao, Y.; Gao, T.; Lan, S.; Simalou, O.; Zhou, X.; Zhang, Y.; Harnoode, C.; Gao, G.; Dong, A. Insight into Biological Effects of Zinc Oxide Nanoflowers on Bacteria: Why Morphology Matters. ACS Appl. Mater. Interfaces 2016, 8 (16), 10109-10120.

(20) Pasquet, J.; Chevalier, Y.; Couval, E.; Bouvier, D.; Noizet, G.; Morlière, C.; Bolzinger, M. A. Antimicrobial activity of zinc oxide particles on five micro-organisms of the Challenge Tests related to their physicochemical properties. Int. J. Pharm. 2014, 460 (1-2), 92-100.

(21) Gilbert, E.; Pirot, F.; Bertholle, V.; Roussel, L.; Falson, F.; Padois, K. Commonly used UV filter toxicity on biological functions: Review of last decade studies. Int. J. Cosmet. Sci. 2013, 35 (3), 208-219.

(22) Downs, C. A.; Kramarsky-Winter, E.; Segal, R.; Fauth, J.; Knutson, S.; Bronstein, O.; Ciner, F. R.; Jeger, R.; Lichtenfeld, Y.; Woodley, C. M.; et al. Toxicopathological Effects of the Sunscreen UV Filter, Oxybenzone (Benzophenone-3), on Coral Planulae and Cultured Primary Cells and Its Environmental Contamination in Hawaii and the U.S. Virgin Islands. Arch. Environ. Contam. Toxicol. 2015, 1-24.

(23) Liu, H.; Sun, P.; Liu, H.; Yang, S.; Wang, L.; Wang, Z. Acute toxicity of benzophenone-type UV filters for Photobacterium phosphoreum and Daphnia magna: QSAR analysis, interspecies relationship and integrated assessment. Chemosphere 2015, 
E. de Lucas-Gil, F. Rubio-Marcos, P. Leret, B. Motos-Pérez, M. Monte-Serrano, J. Menéndez, J.F. Fernández, Opening a New Gate to Glass Preservative with Long-Lasting Antimicrobial Activity as Replacement of Parabens, ACS Sustain. Chem. Eng. 5 (2017) $294-302$. doi:10.1021/acssuschemeng.6b01609.

$135,182-188$.

(24) Schlumpf, M.; Cotton, B.; Conscience, M.; Haller, V.; Steinmann, B.; Lichtensteiger, W. In vitro and in vivo estrogenicity of UV screens. Environ. Health Perspect. 2001, 109 (3), 239-244.

(25) Schlumpf, M.; Kypke, K.; Vökt, C. C.; Birchler, M.; Durrer, S.; Faass, O.; Ehnes, C.; Fuetsch, M.; Gaille, C.; Henseler, M.; et al. Endocrine Active UV Filters: Developmental Toxicity and Exposure Through Breast Milk. Chim. Int. J. Chem. 2008, $62(5), 345-351$.

(26) Wong, T.; Orton, D. Sunscreen allergy and its investigation. Clin. Dermatol. 2011, 29 (3), $306-310$.

(27) Smijs, T.; Pavel, S. Titanium dioxide and zinc oxide nanoparticles in sunscreens: focus on their safety and effectiveness. Nanotechnol. Sci. Appl. 2011, 4 (1), 95.

(28) Filipe, P.; Silva, J. N.; Silva, R.; Cirne de Castro, J. L.; Marques Gomes, M.; Alves, L. C.; Santus, R.; Pinheiro, T. Stratum Corneum Is an Effective Barrier to $\mathrm{TiO}_{2}$ and $\mathrm{ZnO}$ Nanoparticle Percutaneous Absorption. Skin Pharmacol. Physiol. 2009, 22 (5), 266-275.

(29) Wu, J.; Liu, W.; Xue, C.; Zhou, S.; Lan, F.; Bi, L.; Xu, H.; Yang, X.; Zeng, F.-D. Toxicity and penetration of TiO 2 nanoparticles in hairless mice and porcine skin after subchronic dermal exposure. Toxicol. Lett. 2009, 191 (1), 1-8.

(30) Jiménez Reinosa, J.; Leret, P.; Álvarez-Docio, C. M.; del Campo, A.; Fernández, J. F. Enhancement of UV absorption behavior in $\mathrm{ZnO}-\mathrm{TiO}_{2}$ composites. Boletín la Soc. Española Cerámica y Vidr. 2016, 55 (2), 55-62.

(31) Nakamoto, K. Infrared and Raman Spectra of Inorganic and Coordination Compounds, Sixth.; John Wiley \& Sons, Inc.: Hoboken, NJ, USA, 2008.

(32) Moustafa, Y. M.; El-Egili, K. Infrared spectra of sodium phosphate glasses. J. Non. Cryst. Solids 1998, 240 (1-3), $144-153$.

(33) Döhler, F.; Mandlule, A.; van Wüllen, L.; Friedrich, M.; Brauer, D. S. ${ }^{31}$ P NMR characterisation of phosphate fragments during dissolution of calcium sodium phosphate glasses. J. Mater. Chem. B 2015, 3 (6), 1125-1134.

(34) Ahmed, I.; Abou Neel, E. A.; Valappil, S. P.; Nazhat, S. N.; Pickup, D. M.; Carta, D.; Carroll, D. L.; Newport, R. J.; Smith, M. E.; Knowles, J. C. The structure and properties of silver-doped phosphate-based glasses. J. Mater. Sci. 2007, 42 (23), 9827-9835.

(35) Abou Neel, E. A.; O’Dell, L. A.; Smith, M. E.; Knowles, J. C. Processing, characterisation, and biocompatibility of zinc modified metaphosphate based glasses for biomedical applications. J. Mater. Sci. Mater. Med. 2008, 19 (4), $1669-1679$.

(36) Brow, R. K.; Phifer, C. C.; Turner, G. L.; Kirkpatrick, R. J. Cation Effects on 31P MAS NMR Chemical Shifts of Metaphosphate Glasses. J. Am. Ceram. Soc. 1991, 74 (6), 1287-1290.

(37) Fernandez, J. F.; Lorite, I.; Rubio-Marcos, F.; Romero, J. J.; García, M. A.; Quesada, A.; Martín-González, M. S.; CostaKramer, J. L. Method for the Dry Dispersion of Nanoparticles and the Production of Hierarchical Structures and Coatings. WO2010010220-A1, 2010

(38) Rubio-Marcos, F.; Calvino-Casilda, V.; Bañares, M. A.; Fernandez, J. F. Novel hierarchical $\mathrm{Co}_{3} \mathrm{O}_{4} / \mathrm{ZnO}_{\text {mixtures by dry }}$ nanodispersion and their catalytic application in the carbonylation of glycerol. J. Catal. 2010, 275 (2), $288-293$.

(39) Rubio-Marcos, F.; Manzano, C. V.; Reinosa, J. J.; Romero, J. J.; Marchet, P.; Martín-González, M. S.; Fernández, J. F. Mechanism of $\mathrm{Ni}_{1-\mathrm{x}} \mathrm{Zn}_{\mathrm{x}} \mathrm{O}$ Formation by Thermal Treatments on NiO Nanoparticles Dispersed over ZnO. J. Phys. Chem. C 2011, 115 (28), 13577-13583.

(40) Pasquet, J.; Chevalier, Y.; Couval, E.; Bouvier, D.; Bolzinger, M. A. Zinc oxide as a new antimicrobial preservative of topical products: Interactions with common formulation ingredients. Int. J. Pharm. 2015, 479 (1), 88-95. 